\title{
Extraordinarily low mortality rates reported in juvenile Pacific oysters in the German Wadden Sea
}

\author{
J. J. Beukema $\cdot$ R. Dekker
}

Received: 24 July 2009/Accepted: 25 July 2009/Published online: 15 August 2009

(C) Springer-Verlag and AWI 2009

In a recent publication in Helgoland Marine Research, Schmidt et al. (2008) report the rapid spread of the Pacific oyster (Crassostrea gigas) into the East Frisian Wadden Sea. They conclude that the observed rapid increase in population size was facilitated by low-mortality rates in juveniles. Particularly for the period between $\sim 0.5$ and $\sim 1.5$ years after settlement, they report extremely low mortality when compared with the next year, when instantaneous mortality rates in the same area and in the same cohort were an order of magnitude higher (compare Table 1). Detailed observations on this oyster cohort in another part of the German Wadden Sea by Diederich (2006) revealed even higher mortality rates for the first half year after settlement, i.e. in the period preceding the one of the supposedly low mortality.

Generally, mortality rates in bivalves decline from high values in fragile spat to much lower levels in robust adult stages. Several examples of such declining trends in agemortality relationships in marine bivalves are available from the literature, e.g. Walne (1961) in Ostrea edulis, Brousseau (1978) in Mya arenaria, Nakaoka (1996) in Yoldia notabilis, and Van der Meer et al. (2001a, b) in Macoma balthica. A reverse pattern of a strongly increasing mortality rates from an age of $\sim 1$ to an age of $\sim 2$ years as reported by Schmidt et al. (2008) appears to be unusual and asks for a specific explanation.

Communicated by H.-D. Franke.

J. J. Beukema $(\bowtie) \cdot$ R. Dekker

NIOZ Royal Netherlands Institute for Sea Research,

P.O. Box 59, Den Burg, Texel, The Netherlands

e-mail: jan.beukema@nioz.nl
Consistent sampling errors in the assessment of numerical densities at the start and/or end of the period of observation are bound to bias estimates of mortality: underestimating initial numbers or overestimating final numbers would both cause an underestimation of mortality. Underestimates of initial numbers could arise from overlooking part of the individuals present. Particularly in the summer of 2003, when initial numbers were estimated, Schmidt et al. (2008) made an enormous effort by determining numbers of small oysters at 15 mussel beds that were each sampled at no less a number than 100 sites of $1 \mathrm{~m}^{2}$ each, resulting in records of many thousands of juvenile oysters. At the time of first sampling, the shell lengths of the oysters mostly amounted to around 40 and $20 \mathrm{~mm}$, respectively, in the two frequently sampled mussel beds, but they ranged down to only $5-10 \mathrm{~mm}$ in both beds. Searching for these small oysters on the mussel clumps was entirely done in the field, as different from the procedure followed by Diederich (2006), who searched the spat with a stereomicroscope in the laboratory. Apparently, Schmidt et al. did not check their field counts in any way.

Overestimates at the end of the observation period might arise from wrongly including individuals of a younger cohort. Allocation to a specific cohort was done using length-frequency distributions. At the time of sampling, the lengths of the individuals of the two cohorts concerned showed substantial overlap. Again, a check is not stated.

Another source of errors might arise from changes in mussel distribution. As oysters were counted exclusively within mussel beds, any change in the size of these beds or in the numbers of mussels within these beds would also affect estimates of oyster numbers. Mussels might move away from beds or immigrate into beds and such moving mussels may or may not bear attached oysters. Although we are not aware of any quantitative studies of oyster 
Table 1 Annual instantaneous mortality rates $\left(z\right.$ in year $^{-1} ; z$ is the ratio of $\ln$ of numerical densities at start and end of the period of observation, multiplied by 365 and divided by length of observation period in days) as estimated for various age groups of the cohort of Pacific oysters born in 2002 in the German Wadden Sea by Diederich (2006) and Schmidt et al. (2008)

\begin{tabular}{llll}
\hline Age (years) & $0.2-0.8$ & 0.8 or $0.7-1.7$ & $1.7-2.6$ \\
\hline$Z$ (year $\left.^{-1}\right)$ & 1.8 & 0.03 and 0.13 & 0.82 and 1.61 \\
Percentage of mortality & 84 & 3 and 12 & 56 and 80 \\
Reference & Diederich (2006) & Schmidt et al. (2008) & Schmidt et al. (2008)
\end{tabular}

Age expressed in years after a heavy settlement supposed to have taken place in September 2002. The $\mathrm{z}$ value for the youngest age group of $0.005 \mathrm{day}^{-1}$ stated by Diederich (2006) was converted to an annual value of 1.8 year $^{-1}$ (by multiplication by a number of days of 365 )

The two values given for the two older age groups refer to two different beds sampled by Schmidt et al. (2008)

Annual mortality values are also shown as percentages of initial numbers

movements, it is well known that mussels are transported over tidal flats and high numbers can be involved in such movements in gale conditions.

The instantaneous annual mortality rates of 0.8 and 1.6 year $^{-1}$ Schmidt et al. (2008) observed in older oysters ( $>1.7$ years, see Table 1$)$ are not particularly low as compared to annual $z$ values found in the Wadden Sea in populations of some bivalves of similar age, e.g. $\sim 0.54$ year $^{-1}$ in Macoma balthica (Van der Meer et al. 2001a), 2 year $^{-1}$ in Cerastoderma edulis (Van der Meer et al. 2001b) and 1.4 year $^{-1}$ in Mytilus edulis (Beukema and Dekker 2007). Only the mortality rates of oysters of an age of around 1 year reported by Schmidt et al. (2008) appear to be exceptional. We conclude that these unusually low mortality rates need corroboration.

\section{References}

Beukema JJ, Dekker R (2007) Variability in annual recruitment success as a determinant of long-term and large-scale variation in annual production of intertidal Wadden Sea mussels (Mytilus edulis). Helgol Mar Res 61:71-86

Brousseau DJ (1978) Population dynamics of the soft-shell clam Mya arenaria. Mar Biol 50:63-71

Diederich S (2006) High survival and growth rates of introduced Pacific oysters may cause restrictions on habitat use by native mussels in the Wadden Sea. J Exp Mar Biol Ecol 328:211-227

Nakaoka M (1996) Size-dependent survivorship of the bivalve Yoldia notabilis (Yokoyama, 1920): the effect of crab predation. J Shellf Res 15:355-362

Schmidt A, Wehrmann A, Dittmann S (2008) Population dynamics of the invasive Pacific oyster Crassostrea gigas during the early stages of an outbreak in the Wadden Sea (Germany). Helgol Mar Res 62:367-376

Van der Meer J, Beukema JJ, Dekker R (2001a) Long-term variability in secondary production of an intertidal bivalve population is primarily a matter of recruitment variability. J Anim Ecol 70:159-169

Van der Meer J, Piersma T, Beukema JJ (2001b) Population dynamics of benthic species on tidal flats: the possible roles of shorebird predation. In: Reise, K. Ecological comparisons of sedimentary shores. Ecological Studies 151, Springer:317-335

Walne PR (1961) Observations on the mortality of Ostrea edulis. J Mar Biol Assoc UK 41:113-122 